\title{
Curriculum vitae: challenges and potential solutions
}

\section{Jaime A. Teixeira da Silva1, Judit Dobránszki², Aceil Al-Khatib ${ }^{3}$ and Panagiotis Tsigaris ${ }^{4}$}

\author{
${ }^{1}$ Independent researcher, P. O. Box 7, Miki-cho post office, Ikenobe 3011-2, Kagawa-ken, 761- \\ 0799, JAPAN \\ ${ }^{2}$ Research Institute of Nyíregyháza, IAREF, University of Debrecen, HUNGARY \\ ${ }^{3}$ Faculty of Dentistry, Jordan University of Science and Technology, JORDAN \\ ${ }^{4}$ Department of Economics, Thompson Rivers University, CANADA
}

\begin{abstract}
An academic usually has a curriculum vitae (CV) or CV summary (resumé) that highlights their professional career paths. CVs contain information which is written by the academic to signal their qualifications and academic achievements to employers, granting agencies, or promotion and tenure committees. Decision makers face numerous problems with CVs as a vehicle that carries important information, including incomplete, outdated, biased, private, as well as falsified and fabricated information. To complicate matters, decision makers themselves could be making biased decisions even when $\mathrm{CV}$ information is complete and accurate due to potential discriminatory practices. There is weak consistency or standardization in implementation internationally, and little verification. This paper proposes a set of guidelines for verifiable, accurate, complete, updated, and public (VACUP guidelines) CVs, whether these be private, institutional, or owned by third parties. For the effective implementation of these guidelines, a new market in which a third party certifies the CV as VACUP-compliant, is recommended.
\end{abstract}

Keywords: accountability; CV; portfolio; professional summary; public record; signaling; transparency

Why is a public curriculum vitae important?

In academic circles, a curriculum vitae (CV) or resumé (i.e., a succinct $\mathrm{CV}$ and best fit criteria of a candidate to suit a job description; Christenbery, 2014; Hicks and Roberts, 2016) plays many important functions. It serves, in the most ideal of cases, as a summary of the important

Address for Correspondence: Jaime A. Teixeira da Silva, email: jaimetex[at]yahoo.com, Judit Dobránszki, email: dobranszki[at]freemail.hu, Aceil Al-Khatib, email: aceil[at]hotmail.com, Panagiotis Tsigaris, email: ptsigaris[at]tru.ca

Article received on the 27th Jan, 2020. Article accepted on the 9th July, 2020.

Conflicts of Interest: The authors declare no conflicts of interest. 
and relevant aspects of that individual's professional background, and lists, in detail, all of the academic achievements that have defined that individual's career path as an academic, including as a method to evaluate research performance and output (Cañibano and Bozeman, 2009). A CV offers a practical and simple solution to factual professional representation and no longer needs to be presented as a hard-copy, in paper, or even on CD-ROMs, as was suggested by Galdino and Gotway (2005), but can now be presented online, as a digital CV or e-CV. Hereafter, for simplicity sake, CV is used throughout the paper. This would include, very broadly, educational awards and degrees, grants and prizes, postdoc, faculty and editorial positions, meetings, congresses and symposia as well as a complete record of publishing in both peer reviewed and non-peer reviewed publications. To non-academics, and even to some academics, a CV might represent a "vanity item" that gloats about that individual's academic past, especially for recruitment purposes. This is because there tends to be a section on skills or personal qualities that highlights - or praises - one's own positive qualities. Others consider that "inauthentic" researchers might use a CV to feign or masquerade contributions to knowledge (p. 9; Dougherty, 2018). A CV is also useful for employment and for promotional purposes, in a gender-independent manner (Steinpreis et al., 1999). Each academic has a different capacity and has achieved personal accomplishments that are unique and most certainly incomparable. In that sense, the CV should not be used as a tool for comparison, to eliminate competition, or as an exclusionary or discriminatory tool, even though it unfortunately does - often - play this role in hiring decisions. CVs play an important role in hiring decisions and discriminatory practices have been observed based on a person's name, gender and race. In a recent meta-analysis study on hiring discrimination, applicants in a minority group suffered substantial additional discrimination after a callback and significantly less job offers than those in the comparable majority group (Quillian et al., 2020). One serious consequence of discriminatory hiring practices is the falsification of CVs to mask elements (e.g., race) that might be discriminated against (Kang et al., 2016). When making assessments using a CV, individuality, career stage, research, teaching and service work loads, and not only productivity or graduate's institutional (i.e., top universities) affiliations, need to be considered, everything else equal.

False information within a CV can have fateful consequences, even years after a flawed or inaccurate $\mathrm{CV}$ has been used. To illustrate the importance of the $\mathrm{CV}$ in current misconduct cases, readers may refer to the Paolo Macchiarini case in which false information on his CV was used to secure a job at Karolinska Institutet in Sweden (Teixeira da Silva, 2017a), a fact that might not have been detected had no CV existed. However, in this day and age of rampant misconduct in research and publishing (Teixeira da Silva, 2017b), there is increasing pressure on the entire community (authors, editors, publishers, academic institutes, ministries of education, and other educational proponents) to coordinate and ensure that CVs represent much more than just a summary of an academic's past. Part of the crisis in trust in academics, born from a reproducibility crisis (Open Science Collaboration, 2015), exists as a result of lax guidelines or rules regarding CVs, or CVs that are outdated, erroneous or fraudulent (Cleary and Horsfall, 2013). Thus, this paper proposes guidelines for verifiable, accurate, complete, updated, and public (VACUP guidelines) for CVs to be a standard international model.

Regarding each of these elements, a CV needs to be verifiable and must thus exist. A CV should also be updated (Cleary and Horsfall, 2013) to reflect the latest status of an academic path. The importance of the period of updating will depend on the frequency of publication and on the discipline, with actively publishing individuals requiring more frequent updates than those that do not publish that much. Accuracy is important to reflect precise dates of positions, and correct meta-data of publications or titles held. CVs should be complete, and there should be no gaps in information, or purposefully omitted information, provided the other side is not 
practicing discrimination, e.g., against minorities. ${ }^{1}$ Some have even suggested listing failures, or having a separate $\mathrm{CV}$ of failures or career lows. ${ }^{2} \mathrm{~A}$ complete list of congresses attended would allow for the assessment of the attendance of predatory congresses, provided that there exists a database of such congresses with detailed and specific criteria that define what makes them "predatory" (Teixeira da Silva et al., 2017). The risk is that the attendance of unscholarly or predatory conferences can be abused to give the illusion of scholarly participation, but used only to "inflate curricula and boost career progression" (p. 193; Cortegiani et al., 2020). Most importantly, even more so when academics are supported by public funding, CVs should be public, in an open access (OA) format, i.e., not encrypted or behind institutional paywalls or password protection. ${ }^{3}$ However, there is the issue of privacy and the protection of rights. ${ }^{4}$ The ability to independently verify the content of an applicant's $\mathrm{CV}$, including their publication record, has practical implications. This was demonstrated by a study that highlighted how $11 \%$ of papers listed by $20 \%$ of applicants to a trauma and surgical critical care fellowship program could not be verified (Branco et al., 2012).

\section{Incomplete CVs are a source of mistrust and opacity in research and publishing}

One of the important aspects underlying the current academic crisis of trust is that individual academics have been allowed, in many cases, total freedom regarding their CVs. This has allowed the existence of a culture where non-VACUP-compliant CVs have become the norm rather than the exception, or where each individual or institution has been able to determine what information can or should appear on a CV, but often with little regulation. Consequently, any academic or member of the public that wishes to independently verify a career- or publishing-related claim regarding that academic may find a completely unregulated environment, ranging widely from no public CV to fully VACUP-compliant CVs. Since academic publishing is an international and transnational phenomenon, an international set of rules that are enforced is required, which we put forward as the VACUP guidelines. With increasing fraud, and improved methods to detect and expose fraud, which some may associate with the open science movement (McKiernan et al., 2016), comes an increase in regulations, verifications and confirmations. As a result of more complex and stringent checks, which could be equated with an Orwellian state of academic publishing, academia is becoming more "militarized" and possibly even over-regulated (Teixeira da Silva, 2016a; Grimm and Saliba, 2017; Aberbach and Christensen, 2018; Morrish, 2020). As a result, extreme events are starting to take place: academics with legendary status are falling from their status quo positions (Teixeira da Silva et al., 2016) as a result of whistle-blowing and public exposure, academic

\footnotetext{
${ }^{1}$ Negative aspects such as suspensions or criminal records are not usually included but would be the responsibility of an auditor: see sections on auditing, enforcement and compliance.

2 https://www.theguardian.com/education/2016/apr/30/cv-of-failures-princeton-professor-publishes-resume-ofhis-career-lows (April 23, 2016; last accessed: June 20, 2020); https://www.princeton.edu/ joha/Johannes_Haushofer_CV_of_Failures.pdf (April 27, 2016; last accessed: June 20, 2020)

${ }^{3}$ Being made public does not necessarily imply that a CV can be used by other academics to conduct research without obtaining official ethics approval. Such research may be intrusive, violate privacy or confidentiality of the individual whose $\mathrm{CV}$ is made available. Whether a CV that is made public is for information only or whether it can also be applied to research, without obtaining consent from the human subject of that $\mathrm{CV}$, needs to be determined by a research ethics board of the institution following ethical guidelines. We caution readers that research on human subjects with publicly available information, such as a public CV, should be done in a way that protects their human dignity, privacy and confidentiality, protects free and informed consent and minimizes harm.

${ }^{4}$ https://eur-lex.europa.eu/eli/reg/2016/679/oj (April 27, 2017; last accessed: June 20, 2020)
} 
witch-hunts and/or take-downs are occurring at record lightning speeds (e.g., Brian Wansink case $^{5}$, from career peak to career destruction, or a boom-to-bust cycle, of about 4-6 months), and highly unexpected black swan events (Teixeira da Silva, 2015) are becoming more common place. Extreme events such as these indicate that CVs are a highly unregulated aspect of academic research and publishing, and thus a potentially large source of fraud.

The fact that CVs are highly unregulated is evidenced by four high profile cases: recently, it was reported that Lisa Riccobene, a director in the Massachusetts medical examiner's office, appeared to have falsely claimed that she had a master's degree. That report came after her employer, an agency responsible for investigating violent and unexplained deaths, learned that Northeastern University had no record of her earning a master's degree in psychology. ${ }^{6}$ In 2007, Marilee Jones, the dean of admissions at the Massachusetts Institute of Technology (M.I.T) admitted that she had fabricated her credentials stating: "I misrepresented my academic degrees when I first applied to M.I.T. 28 years ago and did not have the courage to correct my résumé when I applied for my current job or at any time since." ${ }^{\text {"7 }}$ In 2013, Leslie Cohen Berlowitz, the head of the prestigious American Academy of Arts and Sciences agreed to resign after revelations that she "embellished her résumé" by falsely claiming a doctorate from New York University $^{8}$. And in 2015, the University of Iowa's Faculty Assembly of the College of Liberal Arts and Sciences approved a motion to censure ${ }^{9}$ against the incoming President, Bruce Harreld, for "violating professional ethics" by misrepresentations on his resumé and for failing to cite co-authors for nine of 12 publications listed on his resumé ${ }^{10}$. These four cases confirm that there is generally initially no background check, verification process or standard requirements for CVs of academics applying for higher education positions, despite the fact that the temptation to misrepresent, deceive or lie in order to get ahead is strong in this highly competitive sector. However, post-publication analyses can reveal erroneous or fraudulent elements, and lead to corrections and reparations, as demonstrated by these cases, or in more extreme cases, jail-time, as occurred for Macchiarini for, among other issues "lying in his CV" (Day, 2019).

By standardizing the requirements for CVs, fraud might be curtailed to some extent, dividing academics, journals, publishers and research institutes as either VACUP-compliant or non-compliant. As a likely result, there may - or should be - be negative consequences for nonVACUP-compliant entities, who will gradually be marginalized if they do not adjust to new VACUP-compliant regulations. This paper proposes VACUP guidelines as a tool to verify the professional and academic record of an author.

\section{Signaling theory and the role of CVs}

Signaling theory was developed by Nobel Laureate Michael Spence (Spence, 1974). Signals are used by people to convey information to others in an attempt to solve an asymmetric

\footnotetext{
5 https://www.washingtonpost.com/health/2018/09/20/this-ivy-league-food-scientist-was-media-darling-nowhis-studies-are-being-retracted/ (September 20, 2018; last accessed: June 20, 2020)

6 https://www.bostonglobe.com/metro/2018/05/30/director-medical-examiner-office-appears-have-fabricatedcredentials/lxP6swhaBC15GYKhLwTWyN/story.html?s_campaign=bdc:article:stub (May 30, 2018; last accessed: June 20, 2020)

${ }^{7}$ https://www.nytimes.com/2007/04/27/us/27mit.html (April 27, 2007; last accessed: June 20, 2020)

${ }^{8}$ https://www.boston.com/uncategorized/noprimarytagmatch/2013/07/25/embattled-head-of-american-academyof-arts-and-sciences-resigns-after-questions-about-resume (July 25, 2013; last accessed: June 20, 2020)

9 https://www.insidehighered.com/quicktakes/2015/09/24/iowa-faculty-group-censures-incomingpresident\#.VgP-OrvfwME.twitter (September 24, 2015; last accessed: June 20, 2020)

$10 \mathrm{http} / / \mathrm{www}$.thegazette.com/subject/news/education/higher-education/university-of-iowa-liberal-arts-collegefaculty-rebukes-new-president-20150924 (September 24, 2015; last accessed: June 20, 2020)
} 
informational problem (Connelly et al., 2011). Spence's seminal work considered education as a signaling device which is undertaken by someone (from hereafter named the "sender") in order to communicate to the prospective employer (from hereafter named the "receiver") that they have a higher ability and thus can be employed at a higher wage rate. There is an asymmetry of information between the two parties. The receiver does not know if the person is of high ability and thus productive or not. In order for the receiver to be convinced that the sender is more productive, the sender invests in a signal, education, which is costly. Education is thus a vehicle to communicate to the receiver that (s)he is of higher ability and thus deserves a higher salary. Furthermore, Spence argued that for a signal to be effective the cost of education for a high-ability person has to be lower than the cost to someone of lower ability. It is interesting that one of the first things a $\mathrm{CV}$ includes when it communicates information and signals quality is the past education accomplishments of the sender.

The applicant-sender wants to send information and signals that will increase their chances for the position they are aiming for. The sender decides which information and signals to communicate, via the $\mathrm{CV}$, to the receiver. Usually positive information (i.e., research record sometimes using journal impact factors as signals) is communicated while negative (i.e., a criminal record, retractions, spin, $p$-hacking, manipulation of data and results, biases, etc.) are not sent to receivers as such information would reduce the chances of the sender being selected. In addition, if the sender believes that there is discrimination, they might hide some information from the $\mathrm{CV}$ such as age, gender and other elements associated with minority groups (Derous and Decoster, 2017; Kang et al., 2016; Foley and Williamson, 2018; Hartwell et al., 2020). The sender has an advantage in that they are true insiders of their own private information and can choose what information is signaled to the receiver and what is not via their CV. They can hide some of this information from the CV if it is to their benefit to do so. However, a VACUPcompliant $\mathrm{CV}$ is complete and thus no information, positive or negative, is hidden ${ }^{11}$. In addition, it would be sufficiently tone-neutral in order to avoid a skewed impression and thus would not require impression management (Waung et al., 2017). However, in order to have the sender comply and not hide information there should be a cost/penalty for hiding information that is valuable to the receiver. The cost of signaling information is fundamental for its effectiveness. A costly signal is credible. Credibility is at stake with CVs because preparation is not very costly. Moreover, for the CV to act as an effective signal of quality it must have a lower cost to high quality senders than those senders who are of lower quality or are not qualified. Introducing a penalty is to make the cost higher for those that are not qualified for the position but who attempt to misinform receivers. The above analysis assumes that the receiver is unbiased and does not hire using discriminatory practices, which might not be the case.

A CV has many similarities with financial statements that firms release. Financial statements, such as a balance sheet or income statement, are released in order to provide information. Firms who have information use financial statements as a signaling or communication device to send information to investors, lenders and creditors who lack this information but want to make decisions based on the information contained in such statements. The purpose of a CV is the same as that of financial statements released by firms, namely the transfer of valuable information from one informed party to another party that is uninformed. This comparison is expanded upon later in the paper.

\footnotetext{
${ }^{11}$ A $100 \%$ VACUP-compliant CV is likely impossible, as aspects such as bias, spin, and difficult to track imperfections are usually not visible until post-publication, if detected at all. It is also highly likely that not all errors can be eliminated, and there should be no punitive consequences for honest error, which can easily be reported to prospective employers. However, manipulated facts that result in an erroneous CV should have more forcible consequences, depending on their seriousness, such as rejection, suspension, job loss, etc.
} 


\section{Why is a CV an imperfect communication device and can it be improved?}

Although a CV carries information and signals to the receiver to make decisions, it is usually not sufficient. Additional signals that accompany the $\mathrm{CV}$ are usually required by the receiver, such as submitting a cover letter, interviewing the candidate, requesting reference letters, external assessment of the applicant's work are examples of additional information the receiver requests to make an informed decision. This implies that the $\mathrm{CV}$ is an imperfect communication device that is not very effective to convince the receiver that the sender is of good or suitable "quality". The more information and signals that are sent, the greater the effectiveness of signaling "quality. Information in a CV can be manipulated by the sender if there are no, or limited, costs associated with the creation of a CV. If there are no costs, senders will want to indicate high ability (i.e., skills or "quality") when in fact they may be of low ability. The cost of preparing and sending information via a CV is thus not inversely proportional to the sender's "quality". Hence there is an incentive for senders of low "quality" to make their CV look much richer than it is, in order to achieve the goal they aim to achieve. ${ }^{12}$ This is why additional information beyond the CV, personal or via bibliographic information lists (Dorsch et al., 2018), is usually required. Requiring additional information increases the cost to the sender but also to the receiving party who needs time to verify and check the information and signals. How can a CV be more effective? First, it has to be made more costly to those that do not reveal the truth in their CVs. Dishonest information and signals should not be rewarded, and should have serious consequences, even punishment, if the dishonesty is intentional, provided the other side is playing fair. However, a CV that follows VACUP guidelines may effectively separate CVs of high "quality" relative to those of lower "quality". How can senders be enforced to follow VACUP guidelines? This issue is particularly relevant in the peer reviewer rewards scheme at Publons (Teixeira da Silva, 2020a). The issue of enforcement is dealt with later on in this paper.

\section{Independent versus centralized CVs: real risks of bias and lack of control / enforcement}

Should CVs be independently managed at the academic's discretion, or should the location where a CV is publicly displayed be centrally controlled? Some possible answers and solutions to these questions would be related to the employment status of an academic. Retired or independently operating academics would have to independently manage their CVs, verification could be by peers and the wider academic pool or public, while control would come from potential employees, journals and publishers. In contrast, an academic who is employed by a research institute (or broadly the employer if the context is non-academic, e.g., a commercial company) would likely have to exercise self-management of their CV, but enforcement of the VACUP guidelines could be achieved by their employer. A journal or publisher that would only allow the submission of papers from VACUP-compliant authors would rely on the accuracy of the employer or research institute. As an example, a staff member in the department of human resources could be tasked with verifying that the CVs of all that institute's employees are VACUP-compliant. This would involve additional costs, no doubt, but would bring additional reputational value to that institute. Furthermore, those journals or publishers operating with VACUP guidelines would only accept

\footnotetext{
${ }^{12}$ We draw readers' attention to the issue of "cosmetic" changes to embellish CVs, either to enhance the visual aspect, or to create a false impression. The public face of a CV might change depending on the intended goal. For example, a person trying to score a job might use the CV quite differently to a person showing their CV on a social media platform like Facebook, ResearchGate, or even their peer review CV on Publons, where an intrinsic level of bias exists, i.e., users tend to show their best. Thus, only factual information can be checked and controlled. The rest (visual) is cosmetic.
} 
papers from VACUP-compliant authors. ${ }^{13}$ In this case, empowering publishers is not necessarily a negative aspect because it adds greater ethical responsibilities on their shoulders. To a greater extent, this ensures that individuals they allow to publish on their platforms and in their journals are valid, and that submissions are not from fake authors or identities with fake CVs. This will also provide academics additional power to hold publishers more accountable.

\section{The importance of declared versus undeclared conflicts of interest}

Conflicts of interest (COIs) are relationships - personal or professional - that may influence the outcome of an event, whether this be related to research or publishing. Hidden COIs are thus an increasingly serious problem in academic publishing, and may be starting to express themselves in preprints (Teixeira da Silva, 2017c). Even academic papers that contain COI statements cannot be independently verified at the time of publication, by virtue of the fact that a $\mathrm{COI}$ is situational, and dependent on the time frame of conflicting interests (Fineberg, 2017). Hidden COIs may be exposed during whistle-blowing or post-publication peer review. In some cases, hidden COIs may lead to the retraction of published articles if the authors fail to disclose competing interests. Medical journals are especially strict about undisclosed, i.e., hidden, COIs. For example, in October 2016, Chest, an Elsevier journal, retracted ${ }^{14}$ a study by Nieman et al. (2015) after learning about hidden COIs from a reader ${ }^{15}$, when the authors failed to report having presented in conferences sponsored by Dräger, which manufactures ventilating devices, and having received honoraria and travel remuneration from Dräger. The same authors also failed to report this COI in three more papers published in JAMA Surgery, which they then reported to the editor in Habashi et al. (2016). Unlike the Nieman et al. paper, which was retracted, corrections were issued for the JAMA Surgery papers. ${ }^{16}$ An even greater risk, given the gate-keeper role that editors play in academic publishing (Teixeira da Silva and Dobránszki, 2018), are the gross lack of declared COIs by journal editors on their own CVs or on journal websites (Teixeira da Silva et al., 2019).

In the context of biomedical publishing, the hidden COIs described above are not surprising and may be more common that many would like to believe. Rasmussen et al. (2015) investigated the prevalence of disclosing COIs by 318 Danish non-industry employed physicians who authored 100 clinical trial reports, and found that $13 \%$ of the 318 authors did not disclose the trial sponsor or manufacturer of the trial drugs, when Rasmussen et al. extracted the names and COI statements of the 318 Danish non-industry employed physicians from the Danish Registry of Authorization to Practice Medicine ${ }^{17}$, they concluded that in trial reporting, 136 of the 318 authors they investigated, $43 \%$ had undisclosed COIs with any drug manufacturer. Rasmussen et al. (2015) could have used VACUP-compliant authors' CVs, had there been any, instead of having to check the Danish Registry of Authorization to Practice Medicine and extract the names and COI statements to determine whether a COI did exist or not in clinical trial reporting.

In light of the above examples, having a VACUP-compliant CV would immediately

\footnotetext{
${ }^{13}$ Multiple-author papers would need each author to be VACUP-compliant.

${ }^{14}$ See notice of retraction which describes the reason Chest retracted the article: "the Journal determined that the authors had not conformed to the Journal's Instructions to Authors to disclose all relevant conflicts of interest by failing to disclose major competing interests that are, in the judgment of the Journal, likely to influence interpretations or recommendations". https://journal.chestnet.org/article/S0012-3692(16)57628-4/fulltext (last accessed: June 20, 2020)

15 https://retractionwatch.com/2017/01/19/undisclosed-conflicts-often-lead-corrections-not-always/ (January 19, 2017; last accessed: June 20, 2020)

${ }^{16}$ https://jamanetwork.com/journals/jamasurgery/fullarticle/2547677 (December, 2016; last accessed: June 20, 2020)

${ }^{17}$ Rasmussen et al. extracted COI statements from the National Board of Health. Danish Authorisation Register.
} 
eliminate the risks of hidden COIs, because it would allow would-be employers or academic institutional management to assess actual or possible COIs and then advise the author as to what should be stated in a published paper. In other words, rather than the author being fully responsible for the COI statement in an academic paper, there would be an interaction with the author's research institute to seek advice as to what constitutes actual or possible COIs. These would then be listed both on the VACUP-compliant CV, as well as in published academic papers. VACUP-compliant CVs and journals or publishers operating with the VACUP guidelines might eliminate the need for the International Committee of Medical Journal Editors (ICMJE) COI form, since COIs would be covered by the all-encompassing CV.

\section{What information should a VACUP-compliant CV contain?}

Below we list, in no particular order, broad and detailed aspects of a CV that would make it VACUP-compliant. These include, based on Galdino and Gotway (2005), Flannery et al. (2014), Price (2014), and Hicks and Roberts $(2016)^{18}$ :

1) A list of undergraduate and graduate degrees obtained, including the period of study (month, year), the full name of the institute and the degree obtained, and the country where the degree was obtained. Such degrees include, for the sciences, BSc, MSc, or PhD degrees, for the arts, BA, MA, or PhD degrees, and for the medical sciences, MD, licensure, residency certificate and board certification. In addition, special degrees conferred, including honorary professorships, honorary doctorates, and honorary fellowships should be clearly listed as such, i.e., as honorary or "by nomination".

2) A list of publications (theses, reports, unpublished documents, preprints, non-peer reviewed papers, peer-reviewed papers, book chapters, and conference papers). Vanity-inducing and meritocracy-based (Vale, 2012) criteria with no or limited academic value such as the Clarivate Analytics' journal impact factor (JIF) (Teixeira da Silva and Bernès, 2018) or Elsevier/Scopus CiteScore (Teixeira da Silva and Memon, 2017; Teixeira da Silva, 2020b) should not be reported in a CV, nor should they be complemented with a wider balance of factors, such as altmetrics, or public bibliometric indexes such as the $h$-index (Cleary et al., 2013). In addition to the vanity-based argument, one of the risks is the inclusion of false positives in Google Scholar profiles which may artificially inflate the academic's $h$-index, so use of this metric in a CV, especially if it is not carefully or accurately curated, will give an inflated perspective of that academic (Teixeira da Silva, 2018).

3) Links to institutional e-portfolios (Baird et al., 2016; Poot, 2016).

4) Awards, fellowships, scholarships, grants.

5) Previous employment.

6) Short description of recent activity.

7) Academic services, memberships and roles in scientific and professional committees, societies, editorial boards.

8) Supervisor and advisor activity in higher education (MSc, $\mathrm{PhD}$, postdoctoral scholars).

9) Collaborations: scientific, industrial, etc.. Supervisor or participant activities in all previous research projects, research funding. The description should be suitable for indicating or excluding any COIs.

10) Languages and the skills in them (reading, speaking and their degree).

\footnotetext{
${ }^{18}$ The purpose of this paper is not to provide advice on structure, style or visual aspects to improve readability; these are aspects that can be gleaned from the references indicated and from a wealth of other general CV-related literature on general biomedical science databases such as PubMed.
} 


\section{The importance of an ombudsman, public relations or liaison officer, and a research integrity office}

A VACUP-compliant CV has little value if the institution where an academic is working is unable to regulate that academic, or to liaise with academics or members of the public that might have non-VACUP-compliant CVs. For this reason, an institute should have an ombudsman, public relations (or liaison) officer (PRO), and a research integrity office (RIO) to deal with queries and/or complaints from the public, including anonymous complaints (Wager et al., 2017). False, misleading or incorrect information in a CV or in a publishing record needs to be reported to an academic, and absent any response from that academic (e.g., that academic is deceased, their email no longer works, or they simply do not respond for any reason), then a university ombudsman, PRO or RIO must be responsible for resolving such issues officially with the complainant within a reasonable amount of time. The same, but reciprocal rule, applies to an academic or member of the public that finds problems with the $\mathrm{CV}$ of an editor or with the $\mathrm{CV}$ of a member of the publishing establishment, including the Committee on Publication Ethics (COPE), which has been without an ombudsman since February, $2016^{19}$, which indicates that any public concerns about COPE members that arise from academics or the public cannot be suitably handled (Teixeira da Silva, 2017d). As for COPE, organizations that are supposed to have an ombudsman, but that do not, decrease trust, and display opacity in issues related to their academics. Since COPE oversees the integrity of the academic literature by its member journals and publishers, which is intricately related to $\mathrm{CVs}$, thus VACUP-compliant CVs should be a serious future consideration by this and other ethical bodies.

\section{Enforcement and certifying that a CV is VACUP-compliant via the private sector}

Having VACUP guidelines is good in theory, but how can they be implemented in practice? Enforcement is difficult and it can be argued that it infringes on individual rights. In addition, requiring and monitoring VACUP-compliant guidelines would be a costly activity. The costs would include resources that would be needed to devote to enforcement and monitoring the VACUP guidelines. This is especially true with small universities or in poorer countries. Who will bear these costs, the employer, the researcher or society in general? It is likely that no one will bear these costs except if there are benefits that will exceed the costs. Since the receiver does not know if the sender is telling or conveying the truth in their CV about their career and qualifications, then the receiver stands to benefit from a CV that is VACUP-compliant because the information will be verifiable, accurate, complete, updated and publicly available. Thus the receiver has an interest for CVs to be VACUP-compliant. The receiver could then ask that a $\mathrm{CV}$ is certified to be VACUP-compliant. Introducing a third party that will certify that CVs are VACUP-compliant for a small fee might be a possible solution. The third party is paid a fraction of the net benefits of the sender and it might be in the interest of the receiver to pay such a fee to certify that the CV is VACUP-compliant.

If certification is a possible solution to adopt VACUP guidelines, then a market needs to be established via a third-party to check and verify if a CV is VACUP-compliant. If both the sender and receiver of the information stand to benefit, then some of these benefits can be shared with the third-party. Since there is a cost for the certification process, those who are low quality or those that want to cheat by providing false information and signals would avoid pursuing certification as they would either be caught cheating or hiding information by a $\mathrm{CV}$

\footnotetext{
${ }^{19}$ https://publicationethics.org/news/applications-cope-ombudsman (February 3, 2016; last accessed: June 20, 2020)
} 
certification third-party ${ }^{20}$. Even if such individuals would be capable of deceiving the thirdparty, it would add to their costs to make such certification less attractive. Certification would separate those that have nothing to hide from those that want to hide information. The receiver would then require that a CV is VACUP-certified. A specialized auditor could offer advice or recommendations as to how to get a CV certified, i.e., VACUP-compliant.

Corporate scandals and accounting frauds caused a U.S. legislation to be enacted in $2002^{21}$ which directs the U.S. Securities and Exchange Commission (SEC) to require CEOs and CFOs of large publicly traded companies to certify that their financial statements are accurate and complete. Certification verifies accuracy and completeness of financial statements ${ }^{22}$. As a result, certification sends a signal to uninformed investors, lenders and creditors that the audited financial statements represent an accurate and complete picture of the organization. Independent external auditors are hired and get paid by the firm to certify that their financial statements and their reporting methods are accurate and comply with Generally Accepted Accounting Principles (GAAP). ${ }^{23}$ The audit signals to the market that management has presented a true picture of financial performance and position. The auditors check and certify that the reports and methods are accurate, complete and that the internal processes are satisfactory.

In order to reduce academic scandals, legislation might be required which mandates senders to certify their CVs are VACUP-compliant. This can be done through external independent auditors. For tenure and promotion, this job is not currently performed by independent external referees who are experts in the area as they examine only the content they are given. The auditors being envisioned are different from external assessors for promotion and tenure decisions. They will be hired and get paid by the senders to certify that their CV complies with the VACUP guidelines. By having the CV audited, the sender signals to the receiver that their CV is VACUP certified, adding academic and employment "value" to the sender. Namely, such a CV would be officially verified for accuracy and completeness, updated and available to the public.

Steps in auditing financial statements are well established and the same process can be applied to auditing and certifying VACUP compliant CVs. Steps are planning the audit, assessing the environment and risk, information gathering, cross checking for accuracy and/or misreporting information, and finally reporting the results of the audit and certifying that a $\mathrm{CV}$ is VACUP-compliant (see hypothetical case study in separate section below).

The process starts with a contract written to audit the sender's CV with full compliance of the sender with the auditor. The next step formalizes the procedures and timing of events of the audit. The auditor then examines the environment and policies of the institution where the sender works and assesses the risks that could lead to material being misrepresented or purposely hidden from the CV. Gathering information and cross checking to verifying information follows. This step is very important as the auditor scans the academic's CV and examines selected documents including cross-checking with journal editors and collaborators and other platforms such as Academia.edu, Google Scholar, ResearchGate, Open Researcher and Contributor ID (ORCID), and Mendeley, to name a few. Once the CV is certified as meeting the VACUP guidelines, it is then made publicly available, but subjected to annual updates. VACUP certification CV would comply to Generally Accepted CV Principles (GACVP).

\footnotetext{
${ }^{20}$ The exception here would be a corrupt certification provider.

${ }^{21}$ See Section 302 of the Sarbanes-Oxley Act: https://www.sec.gov/rules/final/33-8124.htm (August 30, 2002; last accessed: June 20, 2020)

${ }^{22}$ Furthermore executive managers are required to certify that there are internal controls in place with policies and processes that assure trustworthy financial reporting as well as compliance with regulations and the law.

${ }^{23} \mathrm{https}$ //Www.investopedia.com/terms/g/gaap.asp (April 20, 2020; last accessed: June 20, 2020)
} 
It is worth quoting the conclusion of a speech on Financial Reporting and Accounting Fraud by Andrew Ceresney, the Co-Director of the Division of Enforcement of the American Law Institute Continuing Legal Education, Washington, D.C. to the US Securities and Exchange Commission on Sept. 19, 2013 24: "The importance of pursuing financial fraud cannot be overstated. Comprehensive, accurate and reliable financial reporting is the bedrock upon which our markets are based because false financial information saps investor confidence and erodes the integrity of the markets. For our capital markets to thrive, investors must be able to receive an unvarnished assessment of a company's financial condition. Financial reports must provide transparency for investors, and must not obscure the truth, even if that truth is inconvenient. The last decade is full of painful reminders of how important reliable information is to investors, to markets and to regulators. And so, in a post-crisis world, the SEC must renew its focus on financial reporting and accounting so that investors and regulators receive the accurate information that sustains our markets." That speech also concludes: "To wrap this all up, [...] it is imperative that we amplify our efforts to root out financial fraud and ensure that investors receive accurate, transparent, and complete financial information."

Financial statements are UP (updated and publicly available for large organizations) but the problem is VAC which is equivalent to financial statements being accurate, transparent and have complete (ATC) information. If financial statements must be ATCUP so too must CVs be VACUP, to reduce academic and resumé fraud.

\section{Enforcement and certifying that a CV is VACUP-compliant via the public sector}

The enforcement and certification of a CV as being VACUP-compliant would likely only be achieved through the public or private sector. The enforcement and certification via the private market was discussed in the previous section and can be implemented in nations that do not have the resources or public institutions to carry out these transactions as these are costly activities. In the case of government-controlled research institutes or publicly-funded research institutes, an already established government agency could serve as the auditor, while a third party could be required for privately run research institutes. As a hypothetical example, we would look at the US research and education system to offer some perspectives. We assume that three currently existing bodies that already have an established infrastructure, could be involved: the NIH (National Institutes of Health), ORI (Office of Research Integrity), and the IRS (Internal Revenue Service). The NIH would serve as the overseeing body, the ORI would be involved in compliance, while the IRS would be involved with auditing. Since the public funds these agencies through taxes, it is in the interest of tax-paying members of the public that their taxes be used to fund researchers that are acting ethically, and honestly, including having a VACUP-compliant CV. The enforcement triage we suggest brings direct benefit to tax-payers, the government, and to the education system overall.

In the above hypothetical example, let us assume that the IRS discovers, in an annual audit, fake information or errors in a CV of government-employed researcher. Who does the IRS report this error to? There are two possibilities here: a) an honest error or omission in which a short notice to the "sender" (the government-employed academic who is paid by tax-payers money) that the error needs to be fixed, thereby allowing certification to be approved; $b$ ) dishonesty, in which a lie or dishonest action is reported to an ethical entity or legal body, in this case, the NIH and/or ORI. Since both the NIH and ORI are government controlled, both would have interest in only employing academics with VACUP-compliant CVs, thus entrusting such individuals with public funding to conduct research. The receiver, or employer, which in

${ }^{24}$ https://www.sec.gov/news/speech/spch091913ac (September 19, 2013; last accessed: June 20, 2020) 
this case is the US Government (via the NIH), or pockets of specialty researchers such as the USDA (United States Department of Agriculture), could then decide if they employ a person, even if they have retractions. In the latter case, the employer can appreciate that a researcher was honest by reporting the retraction(s), sending also an important signal that retractions should not necessarily be met with a discriminatory response, i.e., VACUP-compliant CVs could be part of the destigmatization of retractions currently plaguing the retraction boom (Teixeira da Silva and Al-Khatib, 2020).

\section{Envisioning a VACUP-compliant vs non-VACUP-compliant academic world}

As indicated earlier in this paper, academic publishing is not without fraud and criminality such as journal hijacking and identity fraud (Dadkhah et al., 2016), or falsifying data and reports to defraud the government. As a result, criminal liability, which may lead to extreme measures, including imprisonment, to counter such non-academic, dishonest or fraudulent behavior, have begun to evolve (Druzin and Li, 2011; Hickman et al., 2019). However, what has been observed is that the crisis is not limited exclusively to authors and academics, but may be extended to editors and editors in chief (EICs), journals, publishers or even research institutes that may be embracing a culture of dishonesty or fraud by abusing their journal's citations, using editorial positions to pad their CVs even though they are not pro-active, or offering protection to corrupt or fraudulent academics among author ranks, all because editors with suitable academic or ethical qualifications were not properly vetted (Teixeira da Silva, 2017e; Teixeira da Silva and Al-Khatib, 2017). The selection of inappropriate or unethical editors can only occur when they do not follow VACUP guidelines and only when VACUP-compliant CVs are publicly available for such editors can such editorial gaffes be eliminated. One example is the removal of Ashutosh Tiwari as the guest editor of a special issue of MDPI's Sensors, after it was discovered that he was using a fake professor title, not only for that special issue, but for other academic activities, including suspect conferences. ${ }^{25}$

As a result, as VACUP guidelines are implemented, a VACUP-compliant vs non-VACUPcompliant academic world will emerge. This will affect trust in individual academics, university rankings, and even funding by funding agencies. Open and transparent academics will reflect positively on their academic institutes and on the journals in which they publish, while VACUP-compliant editors and EICs will allow academics to trust - beyond artificial metrics with no intrinsic academic value (Teixeira da Silva and Bernès, 2018) - an editor board, and by association, a journal or publisher. Consequently, VACUP-compliant CVs will attract funding from agencies that can trust candidates and their research institutes. VACUP-compliant $\mathrm{CVs}$ thus have a net-positive snow-ball impact on research and on the publishing enterprise.

The existence of VACUP-compliant academics, editors/EICs, journals and publishers, and research institutes will then allow any member of the public to determine whether they are predatory (i.e., if their existence is merely to exploit the system to their advantage using opaque, dishonest, unfair or criminal/illegal strategies; Teixeira da Silva, 2013a) or zombified (i.e., they have reached such a level of corruption that they can no longer be deemed to be academic, and yet continue to exist because there is no system in place to expunge them from the system following proof of corruption; Teixeira da Silva, 2016b). In this sense, an institutional RIO is required to ensure that academics and institutional management are VACUP-compliant, while an ombudsman or PR/liaison officer maintains trust in the public domain by offering subjective

\footnotetext{
25 https://www.the-scientist.com/?articles.view/articleNo/51363/title/Sensors--Journal-Pulls-Planned-Special-Issue-Due-to-Guest-Editor-sFake-Credentials/ (January 16, 2018; last accessed: June 20, 2020); https://forbetterscience.com/?s=Ashutosh+Tiwari (last accessed: June 20, 2020)
} 
proof of the academic nature and honesty, openness and transparency of an organization's members, i.e., the academic research institute and its academics. Part of the work portfolio of an institution's PRO/liaison officer would be to ensure that publicly available CVs are accurate and updated. However, if the institution does not have the resources then it can rely on the private sector to certify a CV to be VACUP compliant, similar to private accounting firms and the industry that certifies the financial statements of small, medium and large size firms.

\section{What choices currently exist for non-institutional CVs?}

There are now several privately owned non-institutional platforms that serve as informal systems for academics to show-case or represent their CVs. Some of the largest include Academia.edu, ResearchGate, Google Scholar, ORCID, Mendeley, or Loop, the latter two owned by publishers Elsevier B.V. and Frontiers Media Inc., respectively. However, the content of these CVs is controlled by the academics themselves, and even though some functions are automatic, such as the notice to include a published paper linked with a DOI into a profile soon after publication or indexing, there does not appear to be any control by the platform owners to ensure that the profiles are accurate, update, or complete, thus reducing their functionality as a tool for increasing accountability and reproducibility in academic research and publishing. Even though ORCID ${ }^{26,27}$ was created as a centralized nonproprietary data-base of author identification or disambiguation (Vrabel, 2016), this centralized system is being rapidly adopted and implemented by a vast swathe of publishers hoping to reduce or erase fraudulent authors and peers from their journals, but the transition from a voluntary to a mandatory registration poses serious violations to authors' rights, such as freedom of choice or the right to protest not wishing to belong to this centralized author-registration and verification system (Teixeira da Silva, 2017f). More recently, SciENcv (Science Experts Network Curriculum Vitae ${ }^{28}$ was launched, describing itself as "A researcher profile system for all individuals who apply for, receive or are associated with research investments from federal agencies" (Vrabel, 2016), but its use is limited to the US, and to researchers associated with US federal agencies, hinting at greater accountability. Time will tell if SciENcv and ORCID are VACUP-compliant.

\section{Conclusions}

There are strong parallels between the arguments for or against maintaining the accuracy of the academic record, and maintaining the accuracy of an academic's professional record, or CV. A lot of the literature (PubMed) that can be found prior to the turn of the century, and even up to about 2010, regarding CVs involves hints and tips at how to improve and promote the writing of the content and the visual aspects to make it more attractive to potential employers. Such non-academic, superficial and vanity-based factors continue to plague the true importance of an academic CV. In the current age of a biomedical science publishing landscape that may be in crisis, a CV (institutional or social media-based) can no longer simply represent a biased vanity-based self-representation of one's career. Nor should a CV be used to represent one's publishing career or conference attendance in a biased manner to eliminate so-called "predatory" publications of conferences (Cappell, 2015; Cobey et al., 2017; Moher et al., 2017), or based

\footnotetext{
${ }^{26}$ https://orcid.org/ (last accessed: June 20, 2020)

${ }^{27}$ https://en.wikipedia.org/wiki/ORCID (last accessed: June 20, 2020)

${ }^{28}$ https://www.ncbi.nlm.nih.gov/sciencv/ (last accessed: June 20, 2020)
} 
exclusively on leading or popular databases (Negahdary, 2017), as such approaches skew the reality of a $\mathrm{CV}$, offer only a positive perspective, and do not reflect a complete vision of the academic (Teixeira da Silva and Tsigaris, 2018). Similarly, the impact that publications in lowJIF journals (Donnelly et al., 2019) is irrelevant to their VACUP-compliance, as a CV should carry the list of all publications including in journals with a high, low or no JIF. Curiously, a survey among economists indicated that adding lower-tier publications to a publications record (CV) created a negative impression of the author, relative to a CV that carried only the highertier publications (Powdthavee et al., 2018). Using the VACUP guidelines, this paper puts forward clearer principles by which a CV should be used, what should be included, and advice regarding several aspects of CVs that are pertinent to an evolving publishing landscape. Naturally, CVs should continue to be used in their regular form, for employment or grant applications, but following VACUP guidelines, and they should preferably be integrated within a balanced quantitative system of evaluation, such as the Global Science Factor (Teixeira da Silva, 2013b), that can be independently verified. It is only when a CV is VACUP-compliant that it can be used for research evaluation and then be used for academic and scientific recognition (Youtie et al., 2013).

\section{Limitations of the VACUP guidelines}

While the ideas put forward in this "prototype" paper, and while we have argued for the implementation of the VACUP guidelines for the standardization of CVs for academic, scholarly, tenure and publishing purposes, we recognize that such ideas are only of value if they gain traction and become implemented. Academia as a whole would first have to appreciate the risks to the integrity of their own literature by the existence of false elements such as pseudonymous and fake authors who publish deceptive papers, thereby eroding trust in the journals that they also publish in, in order to appreciate that a validated CV could be the first step towards an integrated ethics-based value system in academic publishing. As one example, had three Springer Nature (Springer Open) journals (Advances in Difference Equations, Fixed Point Theory and Applications, and Journal of Inequalities and Applications) employed the VACUP guidelines, most likely Beatriz Ychussie, a fake author, would likely not have been able to submit to these journals since Roskilde University in Denmark, would have formally validated the existence of, and the credibility of the author, in order to allow for a paper to be submitted to any one of these three journals. For clarity, Beatriz Ychussie was never associated with Roskilde University. The risk with this case - and there are a growing number of cases like it - is that the fraudulent person or group that created the fake Beatriz Ychussie is still out there and may have created other false papers, thereby polluting the scientific literature, devaluing the value of these ranked and metricized journals (2-year journal impact factor of 1.510 and 1.136 for Advances in Difference Equations and Journal of Inequalities and Applications, respectively, and a CiteScore of 1.15 for Fixed Point Theory and Applications) with supposed peer review. Those journals and publishers should have, as part of their social and scholarly responsibilities, detected the false entities, to ensure that submitting authors are not fake. However, editorial and publisher responsibility and oversight failed, thereby indirectly causing harm (reputational and otherwise) to other valid authors who have published in those journals. The inability of such publishing entities to effectively pre-screen valid from fake authors may be expanding the predatory publishing market (Teixeira da Silva, 2020c). Thus, only through real cases of fraud, and an understanding of the risks that they pose to all of academia, not only to editors and journals, may be the impetus for academics, editors, journals and publishers to begin to consider the VACUP guidelines as an essential part of publishing's 
academic integrity, when integrated as part of the manuscript submission process. In summary, user risk will stimulate user need and application.

Evidently, the CV of a postdoctoral student or a tenured professor might differ considerably, both in terms of work experience and publications list (quality and quantity). It would thus be erroneous to make direct comparisons between such divergent scholarly profiles in any way. At the same time, the greater the academic path, the greater the risks, so an individual who has 50 publications in their career (or in journals with lower rank) might invite less scrutiny than one with 500 publications (or in journals with higher rank). Thus, risk of scrutiny, usually of problematic literature, may understandably increase with the level of experience of an academic, leaving "lower" ranked or level academics under-scrutinized. The proposed VACUP guidelines to some extent level the playing field by expecting the information in the $\mathrm{CV}$ of a junior academic to be as accurate as that of a senior academic, independent of their individual achievements.

It is important to highlight that although implementing a VACUP-compliant CV is likely to discourage an underestimated number of academics from falsifying their credentials and accomplishments when applying for jobs (Phillips et al., 2019), decision makers should be cognizant of the fact that using a VACUP-compliant CV in hiring decisions is unlikely to eliminate prestige, affiliation or reputational biases which, according to Safón (2019), are influenced by university rankings. Freeman and DiRamio (2016) found that the brand and reputation of an applicant's university influenced selection decisions, as this happens because an affiliation with a top tier university "signals to a search committee that the candidate likely has access to an influential network and has been trained to publish in top tier periodicals". Despite their flaws and biases, rankings play a major role in hiring decisions at some universities and in particular universities that strive to increase their global rankings (Bhattacharjee, 2011).

Economic limitations of verification for universities from poorer nations should be considered. It might be very difficult for smaller institutions to have the financial resources to have positions such as an ombudsman, PRO or RIO to deal with ethics-related complaints. While it is possible that developed nations could afford such an infrastructure, this may not be the case for poorer nations. In order to overcome this financial constraint, we recommend the development of a market whose role as a third part is to certify that CVs are VACUP-compliant, or not, as discussed in the section on the enforcement and certification of the VACUP compliance of a CV via the private sector. The creation of this market will need to be monitored, but it will also create jobs for both underdeveloped and developed nations, releasing the need to spend resources on a monitoring system within the institute or via the public sector.

\section{References}

Aberbach, J. D., Christensen, T. (2018). Academic autonomy and freedom under pressure: Severely limited, or alive and kicking? Public Organization Review 18(4): 487-506. CrossRef

Baird K, Gamble J, Sidebotham M. (2016). Assessment of the quality and applicability of an e-portfolio capstone assessment item within a bachelor of midwifery program. Nurse Education in Practice 20: 11-16. CrossRef

Bhattacharjee, Y. (2011). Saudi universities offer cash in exchange for academic prestige. Science Magazine 334(6061): 1344-1345. CrossRef

Branco BC, Inaba K, Gausepohl A, Okoye O, Teixeira PG, Breed W, Lam L, Talving P, Sullivan M, Demetriades D. (2012). Nonverifiable research publications among applicants to an academic trauma and surgical critical care fellowship program. Journal of the 
American College of Surgeons 215(3): 337-342. CrossRef

Cañibano, C., Bozeman, B. (2009). Curriculum vitae method in science policy and research evaluation: the state-of-the-art. Research Evaluation 18(2): 86-94. CrossRef

Cappell, M.S., (2015). List predatory journal publications separately from genuine scholarly publications as standard for CVs. British Medical Journal 350, p.h2470. CrossRef

Christenbery, T.L. (2014). The curriculum vitae: gateway to academia. Nurse Education 39(6): 267-268. CrossRef

Cobey, K.D., Mazzarello, S., Stober, C., Hutton, B., Moher, D., Clemons, M. (2017). Is this conference for real? Navigating presumed predatory conference invitations. Journal of Oncology Practice 13(7): 410-413. CrossRef

Connelly, B.L., Certo, S.T., Ireland, R.D., Reutzel, C.R. (2011). Signaling theory: A review and assessment. Journal of Management 37(1): 39-67. CrossRef

Cortegiani, A., Manca, A., Giarratano, A. (2020). Predatory journals and conferences: why fake counts. Current Opinion in Anaesthesiology 33(2):192-197. CrossRef

Dadkhah, M., Maliszewski, T., Teixeira da Silva, J.A. (2016). Hijacked journals, hijacked websites, journal phishing, misleading metrics and predatory publishing: actual and potential threats to academic integrity and publishing ethics. Forensic Science, Medicine, and Pathology 12(3): 353-362. CrossRef

Day, M. (2019). Disgraced tracheal transplant surgeon is handed 16 month prison sentence in Italy. British Medical Journal 16676. CrossRef

Derous, E., Decoster, J. (2017). Implicit age cues in resumes: subtle effects on hiring discrimination. Frontiers in Psychology 8: 1321. CrossRef

Donnelly, K., McKenzie, C.R.M., Müller-Trede, J. (2019). Do publications in low-impact journals help or hurt a CV? Journal of Experimental Psychology: Applied 25(4): 744-752. CrossRef

Dorsch, I., Askeridis, J.M., Stock, W.G. (2018). Truebounded, overbounded, or underbounded? Scientists' personal publication lists versus lists generated through bibliographic information services. Publications 6: 7. CrossRef

Dougherty, M. V. (2018). Introduction. In: Correcting the Scholarly Record for Research Integrity. Research Ethics Forum (Vol. 6), Springer, Cham, Switzerland, pp. 1-18. CrossRef

Druzin B.H., Li, J. (2011). The criminalization of lying: under what circumstances, if any, should lies be made criminal? The Journal of Criminal Law \& Criminology 101(2): 529574.

Fineberg, H.V. (2017). Conflict of interest: why does it matter? JAMA 317(17): 1717-1718. CrossRef

Flannery, A.H., Winstead, P.S., Smith, K.M. (2014). Transforming the curriculum vitae as a new practitioner. American Journal of Health-System Pharmacy 71(24): 2115-2117. CrossRef

Foley, M., Williamson, S. (2018). Does anonymising job applications reduce gender bias? Understanding managers' perspectives. Gender in Management 33(8): 623-635. CrossRef

Freeman Jr, S., DiRamio, D. (2016). Elitism or pragmatism? Faculty hiring at top graduate programs in higher education administration. Journal of the Professoriate 8(2): 94-127.

Galdino, G.M., Gotway, M. (2005). The digital curriculum vitae. Journal of the American College of Radiology 2(2): 183-188. CrossRef

Grimm, J., Saliba, I. (2017). Free research in fearful times: Conceptualizing an index to monitor academic freedom. Interdisciplinary Political Studies 3(1), 41-75. CrossRef

Habashi, N.M., Andrews, P., Nieman, G.F., Kollisch-Singule, M., Bates, J.H. (2016). Failure to disclose conflicts of interest. JAMA Surgery 151(12): 1190. CrossRef

Hartwell, C.J., Orr, T.E., Edwards, J.M. (2020). Reducing online application redundancy: 
Effects on applicant attrition and quality. International Journal of Selection and Assessment 28(2): 200-208. CrossRef

Hickman, C.F., Fong, E.A., Wilhite, A.W., Lee, Y-L. (2019). Academic misconduct and criminal liability: Manipulating academic journal impact factors. Science and Public Policy 46(5): 661-667. CrossRef

Hicks, R.W., Roberts, M.E. (2016). Curriculum vitae: An important tool for the nurse practitioner. Journal of the American Association of Nurse Practitioners 28(7): 347-352. CrossRef

Kang, S.K., DeCelles, K.A., Tilcsik, A., Jun, S. (2016). Whitened résumés: Race and selfpresentation in the labor market. Administrative Science Quarterly 61(3): 469-502. CrossRef

McKiernan, E.C., Bourne, P.E., Brown, C.T., Buck, S., Kenall, A., Lin, J., McDougall, D., Nosek, B.A., Ram, K., Soderberg, C.K., Spies, J.R., Thaney, K., Updegrove, A., Woo, K.H., Yarkoni T. (2016). How open science helps researchers succeed. eLife 5: e16800. CrossRef

Moher, D., Shamseer, L., Cobey, K.D., Lalu, M.M., Galipeau, J., Avey, M.T., Ahmadzai, N., Alabousi, M., Barbeau, P., Beck, A., Daniel, R., Frank, R., Ghannad, M., Hamel, C., Hersi, M., Hutton, B., Isupov, I., McGrath, T.A., McInnes, M.D.F., Page, M.J., Pratt, M., Pussegoda, K., Shea, B., Srivastava, A., Stevens, A., Thavorn, K., van Katwyk, S., Ward, R., Wolfe, D., Yazdi, F., Yu, A.M., Ziai, H. (2017). Stop this waste of people, animals and money. Nature 549(7670): 23-25. CrossRef

Morrish, L. (2020). Academic freedom and the disciplinary regime in the neoliberal university. In: Dawes, S., Lenormand, M. (Eds.) Neoliberalism in Context, Palgrave Macmillan, Cham, Switzerland. pp. 235-253. CrossRef

Negahdary, M. (2017). Live curriculum vitae (CV) of researchers based on Scopus and PubMed databases; a new method in scientometrics. Publishing Research Quarterly 33(3): 297301. CrossRef

Nieman, G. F., Gatto, L. A., Bates, J. H., \& Habashi, N. M. (2015). RETRACTED: Mechanical ventilation as a therapeutic tool to reduce ARDS incidence. Chest 148(6): 1396-1404. CrossRef

Open Science Collaboration (2015). Estimating the reproducibility of psychological science. Science 349(6251): aac4716. CrossRef

Phillips, T., Saunders, R. K., Cossman, J., Heitman, E. (2019). Assessing trustworthiness in research: a pilot study on CV verification. Journal of Empirical Research on Human Research Ethics 14(4): 353-364. CrossRef

Poot, A. (Ed.) (2016). Future ready. Equipping learners for the journey ahead. Pebble Learning Ltd., Telford, UK, 146 pp.

Powdthavee N., Riyanto, Y.E., Knetsch, J.L. (2018). Lower-rated publications do lower academics' judgments of publication lists: evidence from a survey experiment of economists. Journal of Economic Psychology 66: 33-44. CrossRef

Quillian, L., Lee, J. J., Oliver, M. (2020). Evidence from field experiments in hiring shows substantial additional racial discrimination after the callback. Social Forces (in press) CrossRef

Rasmussen, K., Schroll, J., Gøtzsche, P. C., \& Lundh, A. (2015). Under-reporting of conflicts of interest among trialists: a cross-sectional study. Journal of the Royal Society of Medicine 108(3), 101-107. CrossRef

Safón, V. (2019). Inter-ranking reputational effects: an analysis of the Academic Ranking of World Universities (ARWU) and the Times Higher Education World University Rankings (THE) reputational relationship. Scientometrics 121(2): 897-915. CrossRef

Spence, A.M. (1974). Market Signaling: Informational Transfer in Hiring and Related 
Screening Processes (Vol. 143). Harvard University Press.

Steinpreis, R.E., Anders, K.A., Ritzke, D. (1999). The impact of gender on the review of the curricula vitae of job applicants and tenure candidates: A national empirical study. Sex Roles 41(7): 509-528. CrossRef

Teixeira da Silva, J.A. (2013a). Predatory publishing: a quantitative assessment, the Predatory Score. The Asian and Australasian Journal of Plant Science and Biotechnology 7(Special Issue 1): 21-34.

Teixeira da Silva, J.A. (2013b). The Global Science Factor v. 1.1: a new system for measuring and quantifying quality in science. The Asian and Australasian Journal of Plant Science and Biotechnology 7(Special Issue 1): 92-101.

Teixeira da Silva, J.A. (2015). The "black swan" phenomenon in science publishing. Journal of Educational and Social Research 5(3): 11-12. CrossRef

Teixeira da Silva, J.A. (2016a). The militarization of science, and subsequent criminalization of scientists. Journal of Interdisciplinary Medicine 1(2): 214-215. CrossRef

Teixeira da Silva, J.A. (2016b). Do zombie scientists and editors exhibit hubris, or blind courage? Focus on Sciences 2(4): 2 pp. CrossRef

Teixeira da Silva, J.A. (2017a). Ethical ramifications to the Paolo Macchiarini case. Indian Journal of Medical Ethics 2(4): 270-275. CrossRef

Teixeira da Silva, J.A. (2017c). Intellectual phishing, hidden conflicts of interest and hidden data: new risks of preprints. Journal of Advocacy, Research and Education 4(3): 136-146.

Teixeira da Silva, J.A. (2017d). COPE requires greater consistency and accountability. Mediterranean Journal of Social Sciences 8(1): 11-13. CrossRef

Teixeira da Silva, J.A. (2017e). The ethics of peer and editorial requests for self-citation of their work and journal. Medical Journal Armed Forces India 73(2): 181-183. CrossRef

Teixeira da Silva, J.A. (2017f). ORCID: the challenge ahead. European Science Editing 43(2): 34. CrossRef

Teixeira da Silva, J.A. (2018). The Google Scholar h-index: useful but burdensome metric. Scientometrics 117(1): 631-635. CrossRef

Teixeira da Silva, J.A. (2020a). Are negative reviews, predatory reviewers or failed peer review rewarded at Publons? International Orthopaedics (in press) CrossRef

Teixeira da Silva, J.A. (2020b). CiteScore: advances, evolution, applications, and limitations. Publishing Research Quarterly (in press) CrossRef

Teixeira da Silva, J.A. (2020c). An alert to COVID-19 literature in predatory publishing venues. The Journal of Academic Librarianship 46(5): 102187. CrossRef

Teixeira da Silva, J.A., Al-Khatib, A. (2017). How are editors selected, recruited and approved? Science and Engineering Ethics 23(6): 1801-1804. CrossRef

Teixeira da Silva, J.A., Al-Khatib, A. (2020). Ending the retraction stigma: encouraging the reporting of errors in the biomedical record. Research Ethics (in press) CrossRef

Teixeira da Silva, J.A., Bernès, S. (2018). Clarivate Analytics: continued omnia vanitas impact factor culture. Science and Engineering Ethics 24(1): 291-297. CrossRef

Teixeira da Silva, J.A., Dobránszki, J. (2018). Editors moving forward: stick to academic basics, maximize transparency and respect, and enforce the rules. Recenti Progressi in Medicina 109(5): 263-266. CrossRef

Teixeira da Silva, J.A., Dobránszki, J., Al-Khatib, A. (2016). Legends in science: from boom to bust. Publishing Research Quarterly 32(4): 313-318. CrossRef

Teixeira da Silva, J.A., Dobránszki, J., Bhar, R.H., Mehlman, C.T. (2019). Editors must declare conflicts of interest. Journal of Bioethical Inquiry 16(2): 279-298. CrossRef

Teixeira da Silva, J.A., Memon, A.R. (2017). CiteScore: a cite for sore eyes, or a valuable, transparent metric? Scientometrics 111(1): 553-556. CrossRef

Teixeira da Silva, J.A., Sorooshian, S., Al-Khatib, A. (2017). Cost-benefit assessment of 
congresses, meetings or symposia, and selection criteria to determine if they are predatory. Walailak Journal of Science and Technology 14(4): 259-265.

Teixeira da Silva, J.A., Tsigaris, P. (2018). Academics must list all publications on their CV. KOME 6(1): 94-99. CrossRef

Vale, R.D. (2012). Evaluating how we evaluate. Molecular Biology of the Cell 23(17): 32853289. $\underline{\text { CrossRef }}$

Vrabel, M. (2016). Online registries for researchers: Using ORCID and SciENcv. Clinical Journal of Oncology Nursing 20(6): 667-668. CrossRef

Wager E, Kleinert S, Garfinkel M, Bähr V, Baždarić K, Farthing M, Graf C, Hammatt Z, Horn L, King S, Parrish D, Pulverer B, Taylor P, van Meer G (2017). Cooperation and Liaison between Universities and Editors (CLUE): recommendations on best practice. bioRxiv 139170. CrossRef

Waung, M., McAuslan, P., DiMambro, J.M., Mięgoć, N. (2017). Impression management use in resumes and cover letters. Journal of Business and Psychology 32(6): 727-746. CrossRef

Youtie, J., Rogers, J., Heinze, T., Shapira, P., Tang, L. (2013). Career-based influences on scientific recognition in the United States and Europe: Longitudinal evidence from curriculum vitae data. Research Policy 42(8): 1341-1355. CrossRef 